Objectives: To assess disease activity and quality of life in anxious and depressed SpA patients.

Methods: Observational, retrospective, cross-sectional study of SpA patients on bDMARDs, registered at Reuma.pt, Portuguese Rheumatology registry, with $\geq 1$ clinical evaluation from November 2015 to July 2016. Demographic and clinical outcomes including: BASDAI, BASMI, BASFI, ASDAS, DAS 28-3V ESR in peripheral psoriatic arthritis, tender and swollen 44 joints count (TJC, SJC), patients' pain and global assessments, physician's global assessment, CRP, ESR, ASQoL, EQ-5D, FACIT-F for fatigue and HADS scale with 2 domains, HADS-A for anxiety and HADS-D for depression (a cutoff of 8 defining these symptoms), were collected. Statistics: Mann-Whitney test, $p<0.05$. SPSS ${ }^{\circledR}$ v.17.

Results: 160 patients were included, $41.9 \%$ were male, with mean: current age $50.7 \pm 11.9$, age at diagnosis $36.9 \pm 11.96$, at 1 st bDMARD $46.2 \pm 11.8$, time from diagnosis $18.5 \pm 10.3$, years. The mean DAS $28-3 \mathrm{~V}$ ESR was $3.2 \pm 1.4$, BASDAI $2.98 \pm 2.2$, ASDAS 2.4 \pm 1.2 , BASFI 2.68 \pm 2.26 , BASMI 3.36 \pm 1.7 , patient's global assessment $28.8 \pm 24.1$, physician's global assessment 14.5 \pm 15.2 , ESR $18.8 \pm 18.1$ $\mathrm{mm} / \mathrm{h}$, CRP $6.7 \pm 16.01 \mathrm{mg} / \mathrm{L}$, ASQoL 6.2 \pm 5.6 , FACIT-F $37.2 \pm 10.1$ and EQ-5D $0.417 \pm 0.19$. The mean HADS-A was $5.96 \pm 4.01$ and HADS-D was $5.05 \pm 4.1$ (HADS-A $\geq 8$ in $39.5 \%$ and HADS-D $\geq 8$ in $28.3 \%$ patients). Comparison of anxious vs non-anxious and depressive vs non-depressive groups appears on table 1 .

Conclusions: These results suggest that anxious and depressed patients may have higher disease activity, more functional limitations and worse quality of life. These symptoms should not be underestimated, but instead, they should be controlled to achieve clinical improvement.

Disclosure of Interest: None declared

DOI: 10.1136/annrheumdis-2017-eular.5053

\section{SAT0419 SIMILARITIES AND DIFFERENCES BETWEEN HLA B27 POSITIVE AND HLA B27 NEGATIVE SPONDYLOARTHRITIS: RESULTS FROM THE ESPERANZA COHORT}

$\underline{\text { P. Serrano }}^{1,2}$, V. Navarro-Compán ${ }^{2}$, S. Rodríguez ${ }^{3}$, M. Fernández ${ }^{4}$, P. Zarco ${ }^{5}$, E. de Miguel ${ }^{2}$. ${ }^{1}$ Universidad Autónoma; ${ }^{2}$ Hospital la Paz, IdiPaz, Madrid; ${ }^{3}$ Hospital Nuestra Señora de Valme, Sevilla; ${ }^{4}$ Hospital Guadalajara, Guadalajara; ${ }^{5}$ Hospital Fundación Alcorcón, Madrid, Spain

Background: The diagnostic relevance of HLA B27 for spondyloarthritis (SpA) is well established and highlighted by its inclusion in the classification criteria. However, the clinical relevance of this gen on the disease manifestations is unclear.

Objectives: To investigate the influence of HLA B27 status on disease manifestations in patients with recent-onset $\mathrm{SpA}$.

Table 1

\begin{tabular}{|c|c|c|c|c|c|c|}
\hline \multirow[t]{2}{*}{ Characteristic } & \multicolumn{3}{|c|}{ Axial SpA } & \multicolumn{3}{|c|}{ Peripheral SpA } \\
\hline & $\begin{array}{c}\text { HLA-B27+ } \\
\mathrm{N}(\%)=219 \\
(75)\end{array}$ & $\begin{array}{c}\text { HLA-B27- } \\
\mathrm{N}(\%)=72 \\
(25)\end{array}$ & $\overline{p \text { value }}$ & $\begin{array}{c}\text { HLA-B27+ } \\
\mathrm{N}(\%)=28 \\
(33)\end{array}$ & $\begin{array}{c}\text { HLA-B27- } \\
\mathrm{N}(\%)=58 \\
(67)\end{array}$ & $\mathrm{p}$ value \\
\hline Age (years) & $31.4 \pm 7.1$ & $33.8 \pm 6.5$ & 0.01 & $30.6 \pm 8.6$ & $33.9 \pm 7.2$ & 0.07 \\
\hline Male & $151(68.9)$ & $40(55.6)$ & $<0.05$ & $16(57.1)$ & $34(58.6)$ & 0.9 \\
\hline \multicolumn{7}{|l|}{ Symptoms duration } \\
\hline (months) & $12.9 \pm 6.7$ & $13.3 \pm 6.7$ & 0.7 & $8.9 \pm 5.2$ & $9.5 \pm 6.6$ & 0.7 \\
\hline Peripheral arthritis & $44(20.1)$ & $9(12.5)$ & 0.1 & $28(100)$ & $55(94.8)$ & 0.2 \\
\hline Enthesitis & $48(21.9)$ & $9(12.5)$ & 0.08 & $18(64.3)$ & $25(43.1)$ & 0.07 \\
\hline Dactylitis & $13(5.9)$ & $3(4.2)$ & 0.6 & $9(32.1)$ & $19(32.8)$ & 0.9 \\
\hline \multicolumn{7}{|l|}{ EAMs: } \\
\hline - Uveitis & $20(9.1)$ & $3(4.2)$ & 0.2 & $1(3.6)$ & $0(0)$ & NA \\
\hline - Psoriasis & $18(8.2)$ & $15(20.8)$ & $<0.01$ & $2(7.1)$ & $26(44.8)$ & $<0.001$ \\
\hline$-\mathrm{IBD}$ & $4(1.8)$ & $5(6.9)$ & $<0.05$ & $2(7.1)$ & $8(13.8)$ & 0.4 \\
\hline \multicolumn{7}{|l|}{ Diarrhea, cervicitis, } \\
\hline Inflammatory back pain & $\begin{array}{c}9(4.1) \\
83(37.9)\end{array}$ & $\begin{array}{c}2(2.8) \\
29(40.3)\end{array}$ & $\begin{array}{l}0.6 \\
0.7\end{array}$ & $3(10.7)$ & $2(3.4)$ & 0.2 \\
\hline Family history & $84(38.4)$ & $17(23.6)$ & $<0.05$ & $10(35.7)$ & $21(36.2)$ & 0.9 \\
\hline \multicolumn{7}{|l|}{ APRs: } \\
\hline - ESR $(\mathrm{mmHg})$ & $13.6 \pm 13.2$ & $13.5 \pm 14.3$ & 0.9 & $13.8 \pm 14.6$ & $14.2 \pm 12.9$ & 0.9 \\
\hline$-\mathrm{CRP}(\mathrm{mg} / \mathrm{L})$ & $11.3 \pm 15.3$ & $9.4 \pm 14.9$ & 0.4 & $19.5 \pm 48.0$ & $11.0 \pm 18.8$ & 0.2 \\
\hline SJC & $0.3 \pm 1.5$ & $0.2 \pm 0.8$ & 0.8 & $1.6 \pm 3.0$ & $1.3 \pm 2.0$ & 0.6 \\
\hline VAS $(0-10)$ physician & $2.8 \pm 2.2$ & $3.2 \pm 2.1$ & 0.2 & $2.2 \pm 2.2$ & $2.5 \pm 2.2$ & 0.5 \\
\hline VAS $(0-10)$ patient & $4.0 \pm 2.7$ & $4.6 \pm 2.6$ & 0.2 & $2.9 \pm 2.6$ & $3.3 \pm 2.4$ & 0.6 \\
\hline BASDAI & $3.7 \pm 2.3$ & $4.2 \pm 2.2$ & 0.2 & $2.6 \pm 1.7$ & $3.9 \pm 2.4$ & 0.02 \\
\hline BASFI & $2.2 \pm 2.3$ & $2.8 \pm 2.2$ & 0.1 & $1.2 \pm 1.4$ & $1.9 \pm 2.1$ & 0.09 \\
\hline Temporary disability & $19(8.7)$ & $7(9.7)$ & 0.7 & $5(17.9)$ & $13(22.4)$ & 0.7 \\
\hline ASQOL & $5.5 \pm 4.7$ & $7.0 \pm 4.8$ & $<0.05$ & $3.3 \pm 4.0$ & $5.0 \pm 5.3$ & 0.2 \\
\hline
\end{tabular}

Methods: Baseline database from ESPeranza cohort ( $<45$ years, symptoms duration 3-24 months and with inflammatory back pain or asymmetrical arthritis or spinal/joint pain plus $\geq 1 \mathrm{SpA}$ features) was used. Inclusion period in the program was 2008-2011. For this study, 377 fulfilling the ASAS classification criteria for SpA were included. A descriptive analysis was used to compare demographic and clinical characteristics between HLA B27+ and HLA B27patients for both subgroups, axial $\mathrm{SpA}$ and peripheral $\mathrm{SpA}$. Chi- square test for qualitative variables and Student-t test for quantitative variables were employed to compare variables among groups.

Results: A total of 291 patients (75\% B27+ and 25\% B27-) were classified as axial SpA and 86 (33\% B27+ and 67\% B27-) as peripheral SpA. Results (mean -standard deviation- and relative frequencies) are presented in the table. In axial $\mathrm{SpA}, \mathrm{B} 27$ + patients were younger, more frequently males and with a family history of SpA while B27- patients had more frequently psoriasis, IBD and poorer quality of life. In peripheral SpA, B27- had more frequently psoriasis and reported higher BASDAI.

Conclusions: In patients with SpA, HLA B27 status influences on the presentation of the disease. In axial SpA, the presence of B27 is associated with an earlier onset, male predominance and more frequency of family history of SpA. In peripheral SpA, the presence of B27 is linked with lower subjective parameters of disease activity. In both, axial and peripheral SpA, the absence of B27 is associated with psoriasis, IBD and poor quality of life.

Disclosure of Interest: None declared

DOI: 10.1136/annrheumdis-2017-eular.6011

\section{SAT0420 RELATIONSHIP BETWEEN HEALTH-RELATED QUALITY OF LIFE WITH DISEASE ACTIVITY AND FUNCTIONAL STATUS, IN PATIENTS WITH ANKYLOSING SPONDYLITIS}

\section{P. Chiowchanwisawakit, V. Srinonprasert, W. Katchamart. Faculty of Medicine,}

\section{Siriraj Hospital, Mahidol University, Bangkok, Thailand}

Background: Ankylosing spondylitis (AS) is a chronic disease resulting in diminished quality of life $(\mathrm{QoL})$. There was no study regarding QoL in Thai patients with AS.

Objectives: To identify factors associated with quality of life, measured by EuroQol 5-dimension, 5-level questionnaire (EQ-5D-5L), in patients with AS.

Methods: This was a cross-sectional study. Demographic data and outcomes related to health utility or HU [Thai version EQ-5D-5L], disease activity [BASDAI (0-10), ASDAS-ESR or CRP, number of tender (TJC) and swollen joint (SJC), and enthesitis], and functional status [BASFI $(0-10)$ and HAQ (0-3)] were collected. The $\mathrm{HU}$ was calculated on the basis of responses to 5-domains using the Thai value set. Regression analysis was used to explore factors associated with each EQ-5D domain and HU. Multiple models using different outcome measures for disease activity and functional status were performed to identify the best predictive model.

Results: Among 119 AS patients, most (73\%) were male with mean (SD) age of 40.4 (11.6) years. Most (52.9\%) were married and 92 (77.3\%) were employed. The median (IQR) disease duration, BASDAI, BASFI, and HAQ were 7.5 (11.8) years, 3.2 (3.7), 2.3 (4.2), and 0.4 (0.9), respectively. The mean (SD, range) EQ-5D and VAS were $0.75(0.20,-0.24-1.00)$ and $68.8(18.8,10-100)$, respectively. In univariate analysis, higher disease activity, higher functional index score, and more severe peripheral joint involvement were significantly associated with lower $\mathrm{HU}$ and moderate to very severe problem in each EQ-5D domain compared with no to mild problem with $\mathrm{p}<0.05$, except SJC which was not associated with mobility problem. Conversely, age, gender, marital status, and disease duration were not associated with any EQ-5D domains or HU. In multivariate regression analysis, disease activity and functional status were significantly associated with $\mathrm{HU}$ (Table 1), when adjusted for age. The best predictive model using BASDAI, $\mathrm{CRP}$, and $\mathrm{HAQ}$ with adjusted for age correctly predicted $77.4 \%$ of the variance in $\mathrm{HU}$, while using BASFI instead of $\mathrm{HAQ}$ in the same model yielded slightly lower predictive value of $70.7 \%$

Conclusions: Disease activity and functional status were significantly factors related to QoL and HU in patients with AS. To improve QoL, the aim of treatment should be achieve remission or at least low disease activity and improve or at least maintain function.

Disclosure of Interest: P. Chiowchanwisawakit Grant/research support from: Siriraj Research fund, V. Srinonprasert: None declared, W. Katchamart: None declared

DOI: 10.1136/annrheumdis-2017-eular.3155

Abstract SAT0420 - Table 1. Multivariate linear regression analysis of factors associated with the health utility

\begin{tabular}{|c|c|c|c|c|}
\hline Model & Adjusted $\mathrm{R}^{2}$ & Age (yr), Beta $(95 \% \mathrm{Cl})$ & Disease activity, Beta $(95 \% \mathrm{Cl})$ & Functional index, Beta $(95 \% \mathrm{Cl})$ \\
\hline 1 & 0.707 & $0.002(-0.001,0.005)^{\ddagger}$ & $\begin{array}{c}\text { BASDAI: }-0.030(-0.054,-0.006)^{*} \\
\text { CRP: }-0.003(-0.005,-0.002)^{*}\end{array}$ & BASFI: $-0.036(-0.062,-0.011)^{\star}$ \\
\hline 2 & 0.622 & $0.004(0.001,0.007)^{\star}$ & ASDAS-CRP: $-0.049(-0.091,-0.008)^{\star}$ & BASFI: $-0.055(-0.081,-0.029)^{*}$ \\
\hline 3 & 0.592 & $0.003(0.000,0.005)^{\star}$ & ASDAS-ESR: $-0.084(-0.114,-0.054)^{\star}$ & BASFI: $-0.032(-0.049,-0.016)^{*}$ \\
\hline 4 & 0.774 & $0.002(-0.001,0.005)^{\ddagger}$ & $\begin{array}{l}\text { BASDAI: }-0.034(-0.050,-0.017)^{\star} \\
\text { CRP: }-0.002(-0.003,-0.001)^{\star}\end{array}$ & HAQ: $-0.197(-0.270,-0.124)^{\star}$ \\
\hline 5 & 0.722 & $0.003(0.000,0.006)^{\ddagger}$ & ASDAS-CRP: $-0.055(-0.083,-0.026)^{\star}$ & HAQ: $-0.248(-0.319,-0.177)^{\star}$ \\
\hline 6 & 0.695 & $0.003(0.001,0.005)^{\star}$ & ASDAS-ESR: $-0.069(-0.093,-0.046)^{\star}$ & HAQ: $-0.199(-0.250,-0.147)^{\star}$ \\
\hline
\end{tabular}

